\title{
Abstract
}

\section{Profile of Sri Lankan patients with myocardial infarction at younger age}

Bandara HGWAPL ${ }^{1}$, Kodithuwakku NW ${ }^{1}$, Kogulan $\mathrm{T}^{1}$, Jegavanthan $\mathrm{A}^{1}$, Siribaddana $\mathrm{MAH}^{1}$, Ambagammana $\mathrm{DMJMH}^{1}$, Kularatne $\mathrm{A}^{1}$

${ }^{1}$ Cardiology Unit, Teaching Hospital, Kandy, Sri Lanka

Key words: Cardiology, Myocardial infarction, Young patients, Cardiovascular risk factors, Coronary angiography

\section{Introduction}

Coronary Artery Disease (CAD) in the young is a frequently seen health burden in South Asia and it is essential to understand such patients' profile in the local community.

\section{Objectives}

To evaluate the profile of young patients (age $<45$ years) with Myocardial Infarction (MI) presented to Teaching Hospital, Kandy.

\section{Methods}

Retrospective cross-sectional study was conducted on young patients who had acute coronary syndrome. It was conducted from January 2015 to March 2016 at the Cardiology Unit, Kandy.

\section{Results}

A total of 100 patients ( $84 \%$ of males) with a mean age of $39.84 \pm 6.9$ years were reviewed. Smoking was the main risk factor (53\%) followed by increased LDL [LDL $>100 \mathrm{mg} / \mathrm{dl}]$ (39\%), diabetes (24\%), hypertension (19\%), and family history of CAD $(11 \%)$. There were development of shock in $6 \%$ and arrhythmia in $5 \%$ of the study population following the MI.

Angiographically normal coronary arteries were found in $14 \%$. There were $50 \%$ with significant coronary lesions (50-90\% stenosis) and $58 \%$ with critical ( $\geq 90 \%)$ coronary obstruction. Bivascular and trivascular coronary lesions were recorded in $17 \%$ and $14 \%$ respectively, while the majority had univascular lesions (36\%). Only $2 \%$ had significant left main stem involvement. Significant atherosclerotic coronary lesions mainly affected the left anterior descending artery (52\%) followed by right coronary artery (36\%) and left circumflex (18\%) artery. There were $45 \%$ with Chronic Total Occlusions (CTOs), $6 \%$ with coronary artery ectasia and $1 \%$ with slow flow syndrome.

\section{Conclusion}

Univascular disease is frequent among young patients, in whom smoking and dyslipidemia are the commonest modifiable risk factors. Addressing these issues may play an important role in primary and secondary prevention. 